\title{
Graded Prognostic Assessment
}

National Cancer Institute

\section{Source}

National Cancer Institute. Graded Prognostic Assessment. NCI Thesaurus. Code C140882.

A prognostic index for patients with brain metastases. The GPA incorporates age, Karnofsky performance status, number of extracranial metastases, and number of brain metastases. 